\title{
Electrochemical Synthesis of Phthalides via Anodic Activation of Aromatic Carboxylic Acids.
}

\author{
Davit Hayrapetyan ${ }^{b}$, ViacheslavShkepu ${ }^{b}$, Olzhas T. Seilkhanov ${ }^{c}$, Zhaisan Zhanabil ${ }^{b}$ and Kevin Lam ${ }^{a, b^{*}}$
}

A novel electrochemical synthesis of phthalides was successfully developed using anodically generated aroyloxy radicals in combination with aliphatic carboxylic acid as cheap and readily available alkylating agents' precursors.

Synthetic organic electrochemistry takes its roots from Faradays $^{1 a}$ and Kolbe's ${ }^{1 b}$ classic works on electrolysis of aliphatic carboxylic acids. Although a plethora of transformations have been developed ever since and many of them were successfully used in several industrial processes ${ }^{2}$, the potential of preparative organic electrochemistry remains underestimated. However, the growing impetus to look for greener and cheaper alternatives to classic synthetic methodologies recently lead to the development of novel electrosynthetic methods such as selective allylic oxidation of alkenes $^{4 a}$, trifluoromethylation of heterocycles ${ }^{4 b}$, oxidative homo- and cross-coupling of phenols ${ }^{4 c-e}$ and anilines, ${ }^{4 f}$ intramolecular hydroamidation $\mathrm{n}^{4 \mathrm{~g}}$ and oxidative amidation $\mathrm{n}^{4 \mathrm{~h}}$ of alkenes, oxidative aromatic $\mathrm{C}-\mathrm{H}$ functionalization with formation of benzimidazoles ${ }^{4 i}$ and benzothiazoles ${ }^{4 j}$, cathodic radical deoxygenation ${ }^{4 k}$ or anodic activation of disulphides. ${ }^{41}$ Previously the sequence of an intramolecular addition of an electrochemically generated carbon-centred radical (ECCR) to a double bond followed by a subsequent intermolecular trapping of the newly formed radical by another ECCR was reported for the synthesis of 5 and 6 member carbo- and hetercycles. ${ }^{4}$ Inspired by Marko's methodology which uses electron deficient double bonds to trap the electrochemically generated nucleophilic radical ${ }^{5}$ we decided to investigate the possibility to

a. Department of Pharmaceutical, Chemical and Environmental Sciences, Faculty of Engineering and Science, University of Greenwich, Central Avenue, Chatham Maritime, Chatham, Kent ME4 4TB, United Kingdom k.lam@greenwich.ac.uk

b. Department of Chemistry, Nazarbayev University, 53 KabanbayBatyr Avenue, 010

000 Astana, Republic of Kazakhstan - email: kevin.lam@nu.edu.kz

c. Laboratory of Engineering Profile NMR Spectroscopy Sh. Ualikhanov Kokshetau

State University, Abay Str., 76, 020000 Kokshetau, Republic of Kazakhstan

+ Footnotes relating to the title and/or authors should appear here. extend this methodology to electrogenerated oxygen centred aroyloxyradicals to produce phthalides as synthetically valuable (Fig 1$)^{6}$ building blocks (Scheme 1 ).
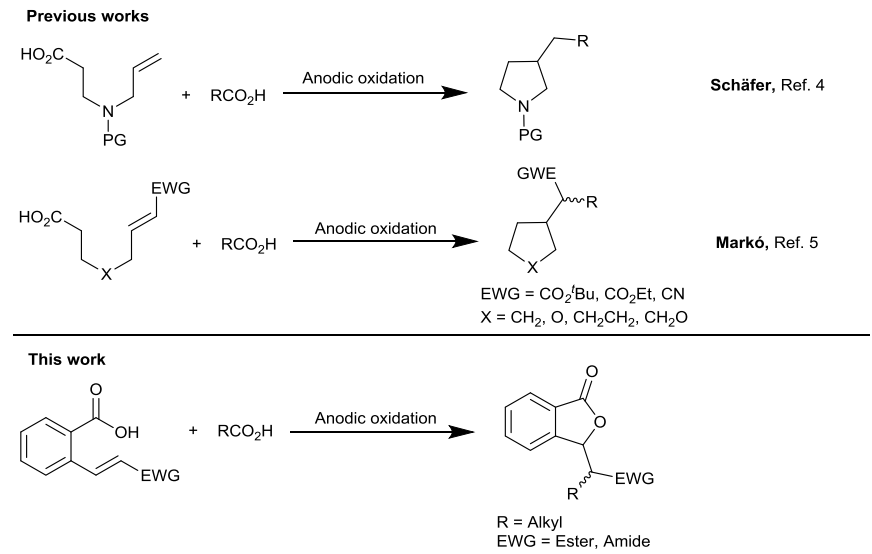

Scheme 1 Comparison of $C$ and $O$ cantered radical cyclizations

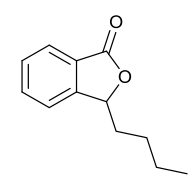

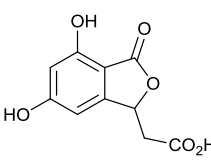

Herbaric acid

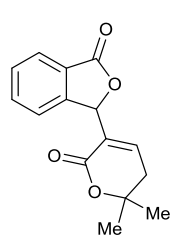

Catalpalactone

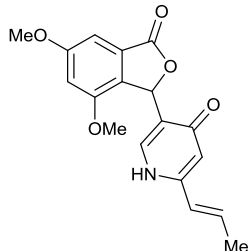

Penicidone $A$
Figure 1 Some naturally occurring phthalide derivatives

Whereas the anodic oxidation of aliphatic carboxylic acids is a wellknown process that has been extensively studied and used in order to generate carbon-centred radicals under mild electrochemical conditions, much to our surprise, the aromatic carboxylic acids have been reported to be unreactive toward standard Kolbe electrolysis conditions. $^{7}$ Their higher oxidation potential compared to aliphatic acids (1.9 V vs. SCE for benzoic acid ${ }^{8}$ and $1.24 \mathrm{~V}$ vs. SCE for acetic $\operatorname{acid}^{9}$ ) or their adsorption mode on the electrode ${ }^{7}$ might impede their direct oxidation in methanol. Nevertheless, when oxidized at high potentials under particularly harsh conditions, benzoic acid has been 
reported to lead to the formation of $\mathrm{CO}_{2}$ as well as many sideproducts $^{10}$.

Herein we would like to disclose a new, mild and ecologically friendly electrochemical method to generate arolyloxy radicals and its use for the preparation of phthalides.

We started our investigations on the electrochemical lactonization of $1 \mathbf{a}$ in the presence of acetic acid as a model reaction (scheme 2). Much to our delight, the desired lactone 2a was cleanly obtained in good yield and the non-alkylated lactone 3a appeared to be the major side product of the reaction (scheme 2 ).

Various parameters, such as the nature of the base, the amount of co-acid or the current density were screened in order to optimize the reaction conditions. Some of the salient results are collected in Table 1 . As previously observed, no reaction occurred in the absence of aliphatic co-acid (entry 1). As expected, the yield of the desired lactone increased with the concentration of the aliphatic co-acid (entries 3 to 6 ). This could easily be rationalized by the fact that a higher concentration of acetic acid generates a larger amount of methyl radicals and therefore favours the formation of the desired product $\mathbf{2 a}$ over the non-alkylated lactone 3a. Unfortunately, pure acetic acid was found to be a poorly conductive medium in the absence of an additional co-solvent (entry 3 ). Although the best yield was obtained by using 10 equivalents of an aliphatic co-acid (entry $3)$, such an excess of co-acid might be impractical, especially when the co-acid is not commercially available. Therefore, in our view, the use of 5 equivalents of co-acid offers a good compromise (entry 5). The nature of the base used for the reaction showed to have little influence over the yield (entries 5 and 7). Optimal yields were obtained when using a minimum of $100 \mathrm{~mA} . \mathrm{cm}^{-2}$ as the current density. The nature of the solvent revealed to be an important factor influencing the fate of the reaction. Although the best yields were obtained using a mixture of acetonitrile and water (entry 11), those conditions led to the formation of many side products resulting from the decomposition of the solvent itself, which complicated the isolation of the desired product. Therefore, methanol remained the solvent of choice, as for most of the classic Kolbe type reactions (entries 8 to 12 ).

Having delineated a set of conditions for the reaction, ${ }^{11}$ the scope and limitations of the methodology were explored. (scheme 3). Much to our delight, the lactonisation proved to tolerate a wide variety of functional and protecting groups such as amides, esters, chlorides and nitriles. In general, primary aliphatic carboxylic acids led to higher yields and even the bulky neo-pentyl group was installed successfully, although with a slightly lower yield (2d). Unfortunately, secondary and tertiary carboxylic acids failed to provide the desired alkylated lactones. In those cases, only the non-alkylated product 3a was obtained. This could be explained by both the additional steric hindrance of secondary and tertiary radicals, and by the fact that such radicals are known to be readily oxidized to the corresponding carbocations under Kolbe's conditions. ${ }^{2}$
Interestingly, allyl esters (2j) remained untouched due to their preferred $s$-cis conformation, which prevented intramolecular cyclization of the radical $10 .{ }^{12}$

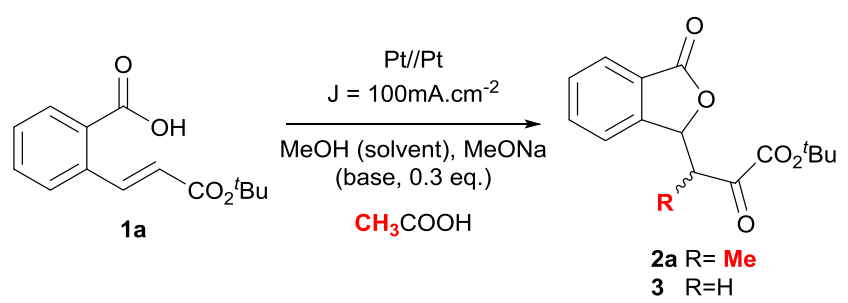

Scheme 2 Anodic lactonization reaction

Table 1. Optimization of the electrolysis conditions

\begin{tabular}{|c|c|c|c|c|}
\hline Entry & Variable & $\begin{array}{l}\mathrm{dr} \text { of } \\
12 \mathrm{a}^{a}\end{array}$ & $\begin{array}{l}\text { Yield of } \\
13^{b}(\%)\end{array}$ & $\begin{array}{l}\text { Yield of } \\
12 a(\%)^{b}\end{array}$ \\
\hline 1 & no $\mathrm{AcOH}$ & - & - & - \\
\hline 2 & $\mathrm{AcOH}$ as solvent & - & - & - \\
\hline 3 & 10 eq. of $\mathrm{AcOH}$ & $1: 1$ & 7 & 74 \\
\hline 4 & 3 eq. of $\mathrm{AcOH}$ & $1: 1$ & 7 & 57 \\
\hline 5 & 5 eq. of $\mathrm{AcOH}$ & $1: 1$ & 8 & $63\left(58^{c}\right)$ \\
\hline 6 & 1.5 eq. of $\mathrm{AcOH}$ & $1: 1$ & 6 & 42 \\
\hline 7 & $\mathrm{NaOH}$ as base & $1: 1$ & 9 & 64 \\
\hline 8 & $\begin{array}{c}\mathrm{MeOH} / \mathrm{H}_{2} \mathrm{O}(10: 1) \\
\text { as solvent }\end{array}$ & $1: 1$ & 3 & 59 \\
\hline 9 & EtOH as solvent & $1: 1$ & n.d. ${ }^{d}$ & 59 \\
\hline 10 & $\begin{array}{c}\mathrm{DMF} / \mathrm{H}_{2} \mathrm{O}(10: 1) \\
\text { as solvent }\end{array}$ & $1: 1$ & 10 & 38 \\
\hline 11 & $\begin{array}{c}\mathrm{CH}_{3} \mathrm{CN} / \mathrm{H}_{2} \mathrm{O}(10: 1) \\
\text { as solvent }\end{array}$ & $1: 1$ & 4 & 69 \\
\hline 12 & $\begin{array}{c}\mathrm{AcOH} / \mathrm{H}_{2} \mathrm{O}(5: 1) \\
\text { as solvent }\end{array}$ & $1: 1$ & n.d. ${ }^{d}$ & 38 \\
\hline
\end{tabular}

${ }^{a}$ determined by NMR analysis of the crude mixture, ${ }^{b}$ determined by NMR analysis of crude mixture using $\mathrm{CHBr}_{3}$ as internal standard, $c$ isolated yield in parenthesis, ${ }^{d}$ not detected by NMR analysis of the crude mixture

In addition, in order to demonstrate the robustness and the versatility of our methodology, we performed the electrosynthesis of the lactone $\mathbf{2 a}$ on a $2 \mathrm{~g}$ scale without noting any significant decrease in yield.

Finally, investigations were conducted in order to shed some light on the reaction mechanism.

As it was mentioned before, no reaction occurred in the absence of an aliphatic acid. Similarly, benzoic acid (4) showed to be completely unreactive under the electrolytic conditions. However, when benzoic acid was subjected to electrolysis in the presence of an excess of aliphatic acid, such as propionic acid (5), we observed the formation of ethyl benzoate (6). The ester formation could be explained by the recombination between the aryloxy radical $4 \mathbf{a}$ and the alkyl radical $5 \mathbf{a}$ formed by Kolbe decarboxylation of the aliphatic acid (scheme 4).

An alternative mechanism would involve the formation of an alkyl carbocation followed by its capture by benzoic acid. Nevertheless, such mechanism is unlikely to happen since the electrolysis of heptanoic acid alone in methanol lead only to the formation dodecane without any traces of methoxyhexane, suggesting the formation of alkyl radicals as the main pathway. 
Two different pathways could account for the formation of aroyloxy radicals $4 \mathbf{a}$ during the reaction. The direct anodic oxidation of the aromatic carboxylate on the electrode would lead the formation of the radical 4 a (pathway I, scheme 4). ${ }^{8}$<smiles>[X]C(=O)OCCOC(C)=O</smiles>

(58\%, $0.4 \mathrm{mmol}$ scale) (52\%, $8.0 \mathrm{mmol}$ scale )<smiles>CCCCOC(=O)[C@H](CC(C)(C)C)C1OC(=O)c2ccccc21</smiles>

2d (31\%)<smiles>CCC[C@H](C(=O)OCC)C1OC(=O)c2ccccc21</smiles><smiles>CCCOC(=O)[C@H](C)C1OC(=O)c2ccccc21</smiles>

2h(42\%)<smiles>C=CCOC(=O)[C@@H](C)C1OC(=O)c2ccccc21</smiles>

2j $(43 \%)$

2k (33\%)<smiles>CCCC(C(=O)OCC)[C@H]1OC(=O)c2ccccc21</smiles>

2b (45\%)<smiles>CCOC(=O)[C@H](C)C1OC(=O)c2ccccc21</smiles>

$2 e(65 \%)$<smiles>CCCCOC(=O)[C@H](CC(C)C)C1OC(=O)c2ccccc21</smiles>

2c (46\%)<smiles>CCOC(=O)[C@H](CC)C1OC(=O)c2ccccc21</smiles>

$2 f(55 \%)$<smiles>CCCCOC(=O)[C@H](CCC(C)=O)C1OC(=O)c2ccccc21</smiles>

$2 \mathrm{~m}(55 \%)$<smiles>CCNC(=O)[C@H](C)C1OC(=O)c2ccccc21</smiles><smiles>CC(C)OC(=O)[C@H](C)C1OC(=O)c2ccccc21</smiles><smiles>CCNC(=O)[C@H](CC)C1OC(=O)c2ccccc21</smiles>

$2 \mathbf{1}(40 \%)$

mechanism where the alkyl radical oxidizes the aromatic carboxylate (pathway II, scheme 4$) \cdot{ }^{13}$

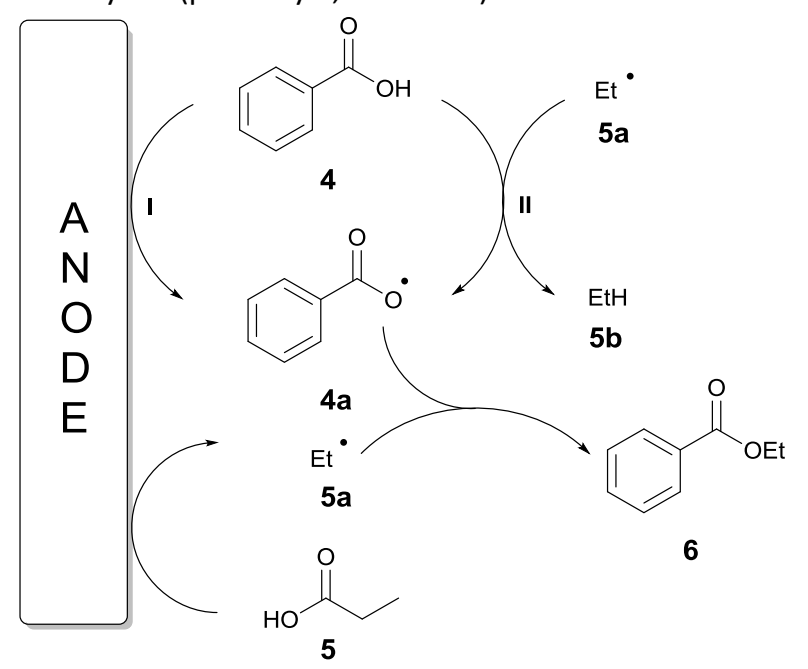

Scheme 4 Proposed mechanism for the anodic esterification of benzoic acid

As a control experiment, ethyl cinnamate (7) was submitted to the bulk electrolytic conditions and was completely recovered from the reaction mixture after 30 minutes of electrolysis. This observation rules out the possible direct oxidation of the olefin into a radical-cation followed by its capture through a nucleophilic attack from the carboxylate.

When the $\mathrm{N}, \mathrm{N}$-diallyl amide $\mathbf{1 g}$ was submitted to anodic oxidation in the presence of an excess of acetic acid, the lactone $\mathbf{8 a}$ was obtained along with non-cyclized compounds $\mathbf{8 b}$ and $\mathbf{8 c}$ as a complex mixture of diasteroisomers (scheme 5). The formation of $\mathbf{8 a}$ strongly supports a radical mechanism where the compound $\mathbf{8 g}$ undergoes a double 5-exo-trig cyclisation.

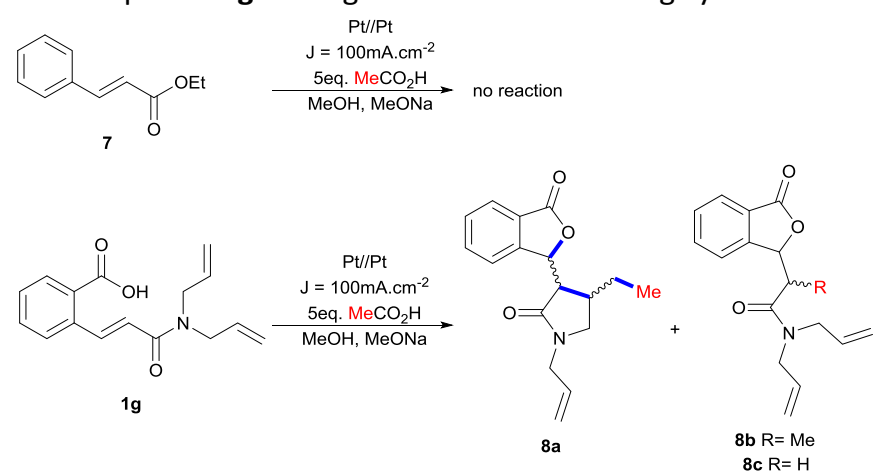

Scheme 5 Electrochemical double radical cyclization

Based on those observations, a possible mechanism would imply the formation of the benzoyloxy radical 9 through either an electron transfer or a hydrogen atom abstraction between $5 a$ and 1a followed by its capture by the double bond and finally, trapping of the resulting radical $\mathbf{1 0}$ by a Kolbe produced alkyl radical (scheme 6). The radical $\mathbf{1 0}$ could also abstract a hydrogen atom from the reaction medium in order to form the non-alkylated lactone 3a. The latter pathway would become predominant when secondary or tertiary carboxylic co-acids are used. 


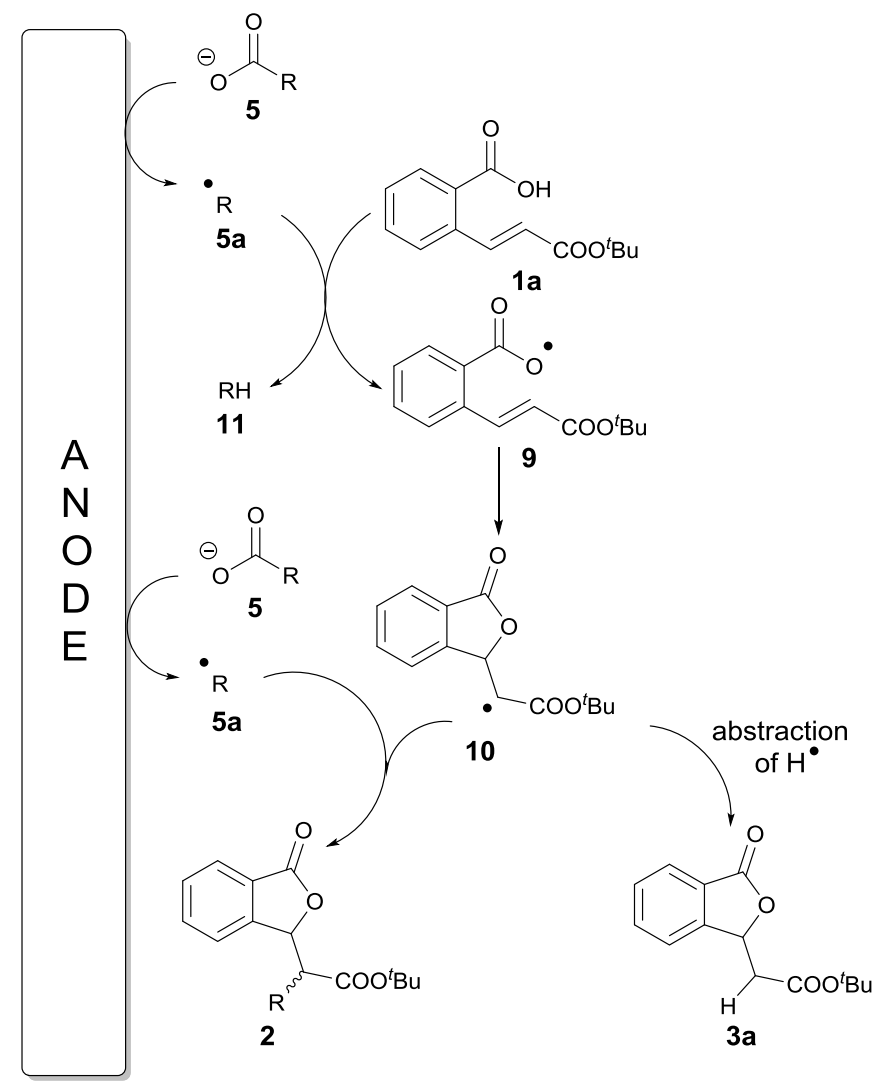

Scheme 6 Proposed mechanism for the anodic lactonization reaction

In summary, we have developed a new electrochemical methodology for the mild and efficient generation of aroyloxy radicals as well as a new practical electrochemical lactonization procedure. Our new method tolerates a wide range of functional groups such as esters, amides, olefins, halides and nitrile. Further studies are now directed toward the complete elucidation of the mechanism using electroanalytical techniques.

\section{ACKNOWLEDGMENTS}

Financial support for this work from Nazarbayev University (ORAU grant for Medicinal Electrochemistry) and the Ministry of Education and Science of Kazakhstan is gratefully acknowledged.

\section{Notes and references}

1 (a) M. Faraday, Philos. Trans. R. Soc. London, 1832, 122, 125-162; (b) H. Kolbe, Justus Liebigs Ann. Chem., 1849, 69, 257-294.

2 Organic Electrochemistry. Revised and expanded, 5th Edn. O. Hammerich, B Speiser Eds. CRC Press, Boca Raton, FL, USA, 2016, 1103

3(a) E. J. Horn, B. R. Rosen, Y. Chen, J. Tang, K. Chen, M. D. Eastgate and P. S. Baran, Nature, 2016, 533, 1-5; (b) A. G. O-Brien, A Maruyama, Y. Inokuma, M. Fujita, P. S. Baran and D. G. Blackmond, Angew. Chemie - Int. Ed., 2014, 53, 11868-11871; (c) B. Elsler, A. Wiebe, D. Schollmeyer, K. M. Dyballa, R. Franke and S. R. Waldvogel, Chem. - A Eur. J., 2015, 21, 12321-12325; (d) S. Lips, A. Wiebe, B. Elsler, D. Schollmeyer, K. M. Dyballa, R. Franke and S. R. Waldvogel, Angew.
Chemie Int. Ed., 2016, 55, 10872-10876; (e) B. Elsler, D. Schollmeyer, K. M. Dyballa, R. Franke and S. R. Waldvogel, Angew. Chemie - Int. Ed., 2014, 53, 5210-5213; (f) L. Schulz, M. Enders, B. Elsler, D. Schollmeyer, K. M. Dyballa, R. Franke and S. R. Waldvogel, Angew. hemie Int. Ed., 2017, 4877-4881; (g) L. Zhu, P. Xiong, Z. Y. Mao, Y. H. Wang, X. Yan, X. Lu and H. C. Xu, Angew. Chemie - Int. Ed., 2016, 55, 2226-2229; (h) P. Xiong, H.-H. Xu and H.-C. Xu, J. Am. Chem. Soc., 2017, jacs.7bo1016; (i) Z. W. Hou, Z. Y. Mao, H. B. Zhao, Y. Y. Melcamu, X. Lu, J. Song and H. C. Xu, Angew. Chemie - Int. Ed., 2016, 55, 9168-9172; (j) X.-Y. Qian, S.-Q. Li, J. Song and H.-C. Xu, ACS Catal., 2017, 2730-2734; (k) K. Lam and I. E. Markó, Org. Lett., 2011, 13. 406-409; (l) K. Lam and W. E. Geiger, J. Org. Chem., 2013, 78, $8020-8027$.

4(a) J. Weiguny and H. J. Schäfer, Liebigs Ann. der Chemie, 1994, 1994, 235-242; (b) A. Matzeit, H. J. Schäfer, C. Amatore, Synthesis, 1995, 1432-1444; (c) M. Huhtasaari, H. J. Schäfer, L. Becking, Angew. Chemie Int. Ed., 1984, 23, 980-981; (d) L. Becking, H. J. Schäfer, Tetrahedron Lett., 1988, 29, 2797-280o.

5 (a) F. Lebreux, F. Buzzo and I. E. Markó, Synlett, 2008, 2008, 2815-2820; (b) F. Lebreux, F. Buzzo and I. Marko, ECS Trans. , 2008, 13, 1-10.

6For naturally occurring phthalide derivatives see (a) L. Ge, S.-K. S. Chan, H.-S. Chung, S.-L. Li, in Studies in Natural Products Chemistry, ed. A. Rahman, Elsevier, Amsterdam, 2005, vol.32, p. 611; (b) J. J. Beck and S.-C. Chou, J. Nat. Prod., 2007, 7o, 891-900; (c) G. Lin, S. S.-K. Chan, H.-S. Chung, S.-L. Li, in Bioactive Natural Products (Part L), ed. Atta-ur-Rahman, Elsevier, 2005, vol. 32, Part L, pp. 611669; (d) K. Kiyoshi, N. Mitsuo, Chem. Lett., 1974, 3, 1491-1492; (e) R. Jadulco, G. Brauers, R. A. Edrada, R. Ebel, V. Wray, P. Proksch, J. Nat. Prod., 2002, 65, 730-733. For bioactive synthetic phthalides see (f) T. V Hung, B. A. Mooney, R. H. Prager and J. M. Tippett, Aust. J. Chem., 1981, 34, 383-395; (g) K. Knepper, R. E. Ziegert, S. Bräse, Tetrahedron, 2004, 6o, 8591-8603; (h) H. Yang, G. Y. Hu, J. Chen, Y. Wang and Z. H. Wang, Bioorganic Med. Chem. Lett., 2007, 17, 5210-5213; (i) R. A. Limaye, V. B. Kumbhar, A. D. Natu, M. V. Paradkar, V. S. Honmore, R. R. Chauhan, S. P. Gample and D. Sarkar, Bioorganic Med. Chem. Lett., 2013, 23, 711-714.

7H. J. J. Schäfer, Top. Curr. Chem., 1990, 152, 91-151.

8Y. Matsuda and K. Kimura, Bull. Chem. Soc. Jpn., 1973, 46, 430434.

9B. Jaun, J. Schwarz and R. Breslow, J. Am. Chem. Soc., 1980, 102, 5741-5748.

10 F. Fichter and E. Uhl, Helv. Chim. Acta, 1920, 3, 22-39.

11 Standard electrolysis procedure: A pre-cooled (ice bath or cold tap water flow) undivided electrochemical cell, equipped with two platinum electrodes $\left(2 \mathrm{~cm}^{2}\right.$ - separated from each other by $\left.1 \mathrm{~mm}\right)$ was charged with a solution of-(2-carboxyvinyl)-benzoic acid derivative $\mathbf{1}(0.4 \mathrm{mmol})$ in $10 \mathrm{~mL}$ of methanol and with an aliphatic carboxylic co-acid (2.0 mmol, 5 equivalents). Then, a few drops of a $3 \mathrm{M}$ solution of MeONa were added in order to reach a current of $200 \mathrm{~mA}$. The mixture was then vigorously stirred and electrolysed for 40 minutes. The solvent was removed under reduced pressure, the residue was dissolved in DCM and washed with water (in case of acetic acid) or $10 \% \mathrm{~K}_{2} \mathrm{CO}_{3}$ (higher aliphatic acids), dried with $\mathrm{Na}_{2} \mathrm{SO}_{4}$ and the solvent was removed under reduced pressure. The diastereomeric ratio was determined directly from the crude mixture by ${ }^{1} \mathrm{H}$ NMR. The mixture was then purified over silica gel using column chromatography along with a petroleum ether/ethyl acetate mixture as the eluent in order to yield the pure lactones 2.

12 D. M. Pawar, A. A. Khalil, D. R. Hooks, K. Collins, T. Elliott, J. Stafford, L. Smith and E. A. Noe, J. Am. Chem. Soc., 1998, 120, 21082112.

13 M. Galicia, M. A. González-Fuentes, D. P. Valencia and F. J. González, J. Electroanal. Chem., 2012, 672, 28-33. 